\title{
Clinical Outcome of Intracameral Dexamethasone in Paediatric Cataract Surgery in a Nigerian Missionary Hospital
}

\author{
S. O. Abu' ${ }^{1}$ A. A. Onua ${ }^{2 *}$, B. Fiebai ${ }^{2}$ \\ ${ }^{1}$ Evangelical Church of West Africa (ECWA) Eye Hospital, Kano, Nigeria \\ ${ }^{2}$ Department of Ophthalmology, University of Port Harcourt Teaching Hospital, Port Harcourt, Nigeria \\ Email: *onuadr@gmail.com
}

How to cite this paper: Abu, S.O., Onua, A.A. and Fiebai, B. (2018) Clinical Outcome of Intracameral Dexamethasone in Paediatric Cataract Surgery in a Nigerian Missionary Hospital. Open Journal of Ophthalmology, 8, 224-231.

https://doi.org/10.4236/ojoph.2018.84026

Received: July 4, 2018

Accepted: November 13, 2018

Published: November 16, 2018

Copyright ( $) 2018$ by authors and Scientific Research Publishing Inc. This work is licensed under the Creative Commons Attribution International License (CC BY 4.0).

http://creativecommons.org/licenses/by/4.0/

\begin{abstract}
Paediatric cataract surgery is associated with several complications among which is high ocular inflammatory response. Conventionally immediate post-operative subconjunctival steroid with adjuvant systemic and frequent topical steroids have been used to control post-operative inflammation. Studies have reported the advantage of intracameral dexamethasone in decreasing postoperative inflammation. Aim: To evaluate the clinical outcome of intracameral dexamethasone in paediatric cataract surgery in Evangelical Church of West Africa (ECWA) Eye Hospital, Kano. Method: This was a prospective study of 694 paediatric cataract surgeries from January 2006 to December 2014. All the patients were given intracameral dexamethasone 0.4 $\mathrm{mg}(0.1 \mathrm{ml})$ immediately after surgery. Each patient had surgical intervention on one eye. Evaluation was done on first, third postoperative day, one week and four weeks later (follow up visits). Outcomes were measured on the fourth week post-operation. Examination of children was done with help of slit lamp for cells, flare or any other sign of inflammation. In case of non-cooperative children examination was done with microscope under sedation/general anaesthesia for fibrinous reaction, exudative membrane, posterior synechiae and red reflex. Results: There were total of 694 patients with age range of 0 to 11 years. Mean age of participants was $2.03 \pm 2.5$ years. The mean duration of cataract before presentation to the hospital was $5.7 \pm 4.3$ months with a range of 0 to 16 months. Post operative complications, likely to be associated with intracameral dexamethasone were corneal opacity $(0.6 \%)$ and raised intraocular pressure (12.5\%). In 31 patients $(4.5 \%)$ there was no post operative complication. Conclusion: Intracameral injection of dexamethasone has a role in preventing immediate postoperative anterior uveitis in paediatric cataract but may not be without complication.
\end{abstract}




\section{Keywords}

Intracameral Dexamethasone, Paediatric Cataract Surgery, Postoperative, Uveitis

\section{Introduction}

Cataract blindness is the leading cause of preventable blindness world-wide. It has been estimated that cataract accounted for $47.8 \%$ of the 37 million people who were blind worldwide in 2002 [1]. In Nigeria, 75 million are estimated to be children under 15 years, out of which 75,000 (1\%) are blind from various causes, the leading cause of which is cataract [2] [3]. The main treatment option for cataract is surgery. Cataract surgery is one of the most commonly performed intraocular surgeries in paediatric ophthalmology. In our environment, cataract surgery by phacoemulsification is available in few centres. Although successful, paediatric cataract surgeries are often attended with post operative complications such as uveitis, glaucoma, posterior capsule opacification, retinal detachment to mention but few. Post operative uveitis can lead to complications like peripheral anterior synechiae, posterior synechiae, exudative membrane and pupil block glaucoma, thus hampering good vision and prolonging rehabilitation period [4].

Conventional attempts to minimize or eliminate post operative inflammations especially uveitis include subconjunctival or sub-tenon's steroid injection and post operative topical and oral steroid therapy. However, topical and oral steroid treatment strategies may be limited and not so effective in the control of post operative inflammation due to non-compliance and also the patient may squeeze his eyes while instilling drops that reduce the contact time of medication in the cornea [4]. Jamil et al. noted that intracameral dexamethasone may be better option than the subconjunctival route of dexamethasone [5]. Subconjunctival injection can cause subconjunctival haemorrhage that can be distressing to the patient. The globe can be accidentally perforated during subconjunctival injection. Subconjunctival injection can cause pain and it is more significant when doing surgery under topical anaesthesia [6]. These disadvantages of subconjunctival injections make intracameral route a better alternative ocular drug delivery route in cataract surgery.

Studies had reported the advantage of intracameral dexamethasone in decreasing postoperative inflammation [2] [3] [4] [7], thus enhancing better postoperative visual outcome and shorter rehabilitation [7]-[14]. Moreover, anterior segment inflammation in terms of posterior synechiae and cell deposits are considered to be minimal when intracameral steroid is used immediately after cataract surgery.

However, some observers have questioned the rational of using intracameral dexamethasone since recent developments in cataract surgical techniques and 
instruments were effective in controlling inflammation in uncomplicated cases and easily managed with only topical steroid drops [11]. Therefore, intracameral injection of steroids in regular cases seems questionable when the side effect of intraocular pressure increase is considered in the long-term.

This study was designed to evaluate the clinical outcome of a single intracameral injection of dexamethasone immediately at the end of uncomplicated phacoemulsification cataract surgeries with intraocular lens implant surgery in children in our local set-up.

\section{Materials and Methods}

This was a prospective study of 694 uncomplicated phacoemulsification paediatric cataract surgeries with intraocular lens implant done at Evangelical Church of West Africa (ECWA) Eye Hospital, Kano, Nigeria from January 2006 to December 2014. All operations were performed by the same surgeon who used the same technique in all eyes and all the patients had intracameral dexamethasone $0.4 \mathrm{mg}(0.1 \mathrm{ml})$ immediately after surgery and received standard postoperative prednisolone and diclofenac eyedrops. Evaluation was also done by the same surgeon on the first, third postoperative day and then one week and four weeks later (follow up visits). Outcomes were measured on the fourth week by subjective complaints, best corrected visual acuity (VA), slit-lamp biomicroscopy, intraocular pressure (IOP) and postoperative complications. In case of non-cooperative children examination was done with microscope under sedation/general anaesthesia for cells, flare, fibrinous reaction, exudative membrane, posterior synechiae and red reflex. The patients' ages, gender, relevant past medical and ocular history, post operative outcome were recorded. Data was analysed with statistical package for social sciences (SPSS) version 20 (IBM Corp. Armonk, NY). Ethical approval for the study was obtained from the relevant institution.

\section{Results}

Mean age of participants was $2.03 \pm 2.5$ years with a range of $0-14$ years. The difference in the ages among participants in the various sexes was not statistically significant $(\mathrm{p}$-value $=0.979)$.

The mean duration of cataract symptom among the participants before presentation to the hospital was $5.7 \pm 4.3$ months with a range of 0 - 16 months.

There was both clinical and statistical difference $(\mathrm{p}=0.000)$ in the post intervention visual acuity in the study. Over 93\% subjects had visual improvement, although this improvement in vision could not be attributable to the intracameral injection only but more to the phacoemulsification cataract surgery.

The increase in the intraocular pressure following the surgical intervention and the intracameral dexamethasone injection was statistically significant ( $\mathrm{p}=$ 0.000 ). The difference in the pre- and post-operative slit lamp findings among the study population was not statistically significant $(\mathrm{p}=0.072)$. 
Post operative complications in this study, likely to be associated with intracameral dexamethasone were corneal opacity $(0.6 \%)$ and raised intraocular pressure (12.5\%). In 31 patients (4.5\%) there was no post operative complication.

\section{Discussion}

This study was conducted to evaluate the clinical outcome of intracameral dexamethasone injections in 694 uncomplicated phacoemulsification paediatric cataract surgeries with intraocular lens implant. In this study, 434 participants (62.5\%) were males and 260 (37.5\%) were females (Table 1). Six hundred and ninety-four eyes were operated (one eye in an individual). This was to minimize the risk of the unknown. It was observed that the average duration of cataract symptom before presentation to the hospital among the study participants was $5.7 \pm 4.3$ months (Table 2).

In this study, post operative complications likely to be attributed to intracameral $0.4 \%$ dexamethasone injection immediately after phacoemulsification cataract surgeries, were corneal opacity $(0.6 \%)$, anterior synaechiae/fibrin formation $(6.2 \%)$, uveitis (3.6\%) raised intraocular pressure (12.5\%). The use of intracameral dexamethasone injections to suppress post operative intraocular inflammation and thereby enhance visual recovery and shorten stay of patients in the hospital has been reported by several authors [9] [10] [13]. Iqbal et al. found that intracameral dexamethasone injection increased its efficacy by about $5 \%$ as compared to subconjunctival route [15]. However, many authors have also

Table 1. Distribution of age group by sex.

\begin{tabular}{|c|c|c|c|c|c|}
\hline \multirow{2}{*}{ Age Group } & \multicolumn{4}{|c|}{ Sex } & \multirow{2}{*}{ Total (Percent) } \\
\hline & M & $(\%)$ & $\mathrm{F}$ & $(\%)$ & \\
\hline $0-12$ months & 250 & $(36.0)$ & 148 & $(21.3)$ & $398(57.3)$ \\
\hline$>1-3$ years & 92 & (13.2) & 58 & $(8.4)$ & $150(21.6)$ \\
\hline$>3-7$ years & 70 & $(10.1)$ & 40 & $(5.8)$ & $110(15.9)$ \\
\hline Above 7 years & 22 & $(3.2)$ & 14 & $(2.0)$ & $36(5.2)$ \\
\hline Total & 434 & $(62.5)$ & 260 & $(37.5)$ & $694(100)$ \\
\hline
\end{tabular}

Pearson Chi-Square Test $=0.194$. $\mathrm{p}$-value $=0.979$

Table 2. Duration of cataract among participants before presentation to the hospital.

\begin{tabular}{ccc}
\hline Duration of Cataract & Frequency & Percent (\%) \\
\hline $0-12$ months & 398 & 57.3 \\
$>3-7$ years & 150 & 21.6 \\
$>7$ years & 110 & 15.9 \\
Total & 36 & 5.2 \\
\end{tabular}


observed that intracameral dexamethasone injections may not be totally without complications [14] [15] [16] [17].

In this study, it was observed that 87 patients representing $12.5 \%$ had raised IOP which was statistically significant $(\mathrm{p}=0.000)$ (Table 3$)$.

Amr Saad Bessa et al. in a similar study in Alexandria, Egypt observed a non-significant increase in intraocular pressure among subjects that had intracameral dexamethasone injection at the end of cataract surgery. The mean IOP increased from $14.98 \pm 2.82 \mathrm{mmHg}$ at baseline to $15.1 \pm 2.82 \mathrm{mmHg}$ by the end of the 30 postoperative day [16]. This observed increase in intraocular pressure agrees with the study of Solaiman et al. in Egypt who observed temporary elevated IOP above normal in 2 eyes (9.5\%) in the study group and in 3 eyes (14.3\%) in the control group [14]. However, like our findings, the transient rise in intraocular pressure was amenable to anti glaucoma drugs within few weeks of administration. However, Praveen et al. in their study of the use of intracameral preservative-free corticosteroid in paediatric cataract surgery observed that there was no intraocular pressure elevation, and that there was no adverse postoperative results [17]. Furthermore, Praveen et al. noted that anterior segment inflammation in terms of posterior synechiae and cell deposits were minimal [17]. However, in our study, anterior synaechiae and fibrin formation were noted in 43 (6.2\%) of our patients while uveitis was observed in 25 (3.6\%) of the patients (Table 4). These observed differences need further investigations as there are many factors that could give raise to these clinical phenomena (rise in IOP and intraocular inflammation) during and after intraocular surgery. In collaboration with our finding, Solaiman et al. in Egypt using 4mg preservative-free triamcinole intracameral injections in 42 eyes found that there was statistically significant higher postoperative inflammatory membrane formation in the control group as compared with his study group [14].

Table 3. Ocular characteristics of the 694 eyes at presentation and $4^{\text {th }}$ week after phacoemulsification surgical intervention.

\begin{tabular}{|c|c|c|c|}
\hline Ocular Parameter & Pre-op No. (\%) & Post-op No. (\%) & p-value \\
\hline \multicolumn{4}{|l|}{ VISUAL ACUITY } \\
\hline $6 / 6-6 / 18$ (Good) & $(-)$ & $314(45.2)$ & \multirow{3}{*}{0.000} \\
\hline$<6 / 18-6 / 60$ (Visual Impairment) & $51(7.3)$ & $338(48.7)$ & \\
\hline CF-NPL (Blind) & $643(92.7)$ & $42(6.1)$ & \\
\hline \multicolumn{4}{|l|}{ INTRAOCULAR PRESSURE (IOP) } \\
\hline Normal IOP (11 - $21 \mathrm{mmHg})$ & $694(100)$ & $607(87.5)$ & \multirow{3}{*}{0.000} \\
\hline Raised IOP ( $\geq 22 \mathrm{mmHg}$ ) & $(-)$ & $87(12.5)$ & \\
\hline Hypotonia ( $\leq 6 \mathrm{mmHg}$ ) & $(-)$ & $(-)$ & \\
\hline \multicolumn{4}{|l|}{ SLIT LAMP MICROSCOPIC FINDINGS } \\
\hline Hyphaemia & $(-)$ & $2(0.3)$ & \multirow{3}{*}{0.072} \\
\hline Keratic Precipitates & $(-)$ & $25(3.6)$ & \\
\hline Flares & $(-)$ & $25(3.6)$ & \\
\hline Anterior Synaechiae/Fibrin Formation & $(-)$ & $43(6.2)$ & \\
\hline
\end{tabular}


Table 4. Post-operative complications.

\begin{tabular}{ccc}
\hline Post-operative complications & Frequencies & Percentage \\
\hline Corneal Opacity & 4 & 0.6 \\
Hyphaema & 2 & 0.3 \\
Raised Intraocular Pressure & 87 & 12.5 \\
Anterior synaechia/Fibrin Formation & 43 & 6.2 \\
Iris Capture/ Incarceration & 9 & 1.3 \\
Uveitis & 25 & 3.6 \\
Posterior Capsular Opacity & 480 & 69.2 \\
Intraocular Lens Dislocation & 6 & 0.8 \\
Vitreous Haemorrhage & 4 & 0.6 \\
Endophthalmitis & 2 & 0.3 \\
Retinal Detachment & 1 & 0.1 \\
No Complication & 31 & 4.5 \\
Total & 694 & 100
\end{tabular}

Intra and postoperative cataract surgical complications may not be exclusively attributable to the use of intracameral dexamethasone as there are many confounding factors ranging from surgeon's skill and expertise, instrumentations and even postoperative care. Inadvertent complications arising from endothelial touch during cataract surgery could give rise to corneal endothelial damage resulting in corneal opacity. Therefore, further investigations and comparative study design are needed to buttress or authenticate our findings. However, unlike our observation, in the work of Jamil et al. it was observed that the use of intracameral dexamethasone at the end of cataract surgery was safe for corneal endothelium [5].

This study is limited in scope as there was no control group to compare the clinical outcome of intracameral dexamethasone in paediatric cataract surgery. Also the follow up period was short. This leaves room for further investigation.

\section{Conclusion}

Intracameral injection of $0.4 \mathrm{mg}$ of dexamethasone at the end of uncomplicated phacoemulsification cataract surgery in children is effective in controlling postoperative ocular inflammation with insignificant minimal complication.

\section{Conflicts of Interest}

The authors declare no conflicts of interest regarding the publication of this paper.

\section{References}

[1] Resnikoff, S., Pascolini, D., Etya'ale, D., Kocur, I., Pararajasegaram, R., Pokharel, 
G.P., et al. (2004) Global Data on Visual Impairment in the Year 2002. Bulletin of the World Health Organization, 82, 844-851.

[2] Frick, K.D. and Foster, A. (2003) The Magnitude and Cost of Global Blindness: An Increasing Problem that Can Be Alleviated. American Journal of Ophthalmology, 135, 471-476. https://doi.org/10.1016/S0002-9394(02)02110-4

[3] Guthoff, R.F. and Schittkowski, M.P. (2007) Childhood Blindness. VISION 2020 and Experiences in an African City. Ophthalmologe, 104, 849-854. https://doi.org/10.1007/s00347-007-1616-8

[4] Ahmad, C.N., Khan, A.A., Siddique, Z. and Ahmed, S. (2010) Role of Intracameral Dexamethasone in Preventing Immediate Postoperative Anterior Uveitis in Paediatric Cataract Extraction. Pakistan Journal of Medical and Health Sciences, 4, 338-342.

[5] Jamil, A.Z., Ahmed, A. and Mirza, K.A. (2014) Effect of Intracameral Use of Dexamethasone on Corneal Endothelial Cells. Journal of the College of Physicians and Surgeons Pakistan, 24, 245-248.

[6] Karalezli, A., Borazan, M. and Akova, Y.A. (2008) Intracameral Triamcinolone Acetonide to Control Postoperative Inflammation Following Cataract Surgery with Phacoemulsification. Acta Ophthalmologica, 86, 183-187. https://doi.org/10.1111/j.1600-0420.2007.01114.x

[7] Mataftsi, A., Dabbagh, A., Moore, W. and Nischal, K.K. (2012) Evaluation of Whether Intracameral Dexamethasone Predisposes to Glaucoma after Pediatric Cataract Surgery. Journal of Cataract \& Refractive Surgery, 38, 1719-1723. https://doi.org/10.1016/j.jcrs.2012.05.034

[8] Yamakiri, K., Uchino, E., Kimura, K. and Sakamoto, T. (2004) Intracameral Triamcinolone Helps to Visualize and Remove the Vitreous Body in Anterior Chamber in Cataract Surgery. American Journal of Ophthalmology, 138, 650-652. https://doi.org/10.1016/j.ajo.2004.05.033

[9] Chang, D.T., Herceg, M.C., Bilonick, R.A., Camejo, L., Schuman, J.S. and Noecker, R.J. (2009) Intracameral Dexamethasone Reduces Inflammation on the First Postoperative Day after Cataract Surgery in Eyes with and without Glaucoma. Clinical Ophthalmology, 3, 345-355. https://doi.org/10.2147/OPTH.S5730

[10] Dieleman, M., Wubbels, R.J., van Kooten-Noordzij, M. and de Waard, P.W. (2011) Single Perioperative Subconjunctival Steroid Depot versus Postoperative Steroid Eyedrops to Prevent Intraocular Inflammation and Macular Edema after Cataract Surgery. Journal of Cataract \& Refractive Surgery, 37, 1589-1597. https://doi.org/10.1016/j.jcrs.2011.03.049

[11] Güngör, S.G., Bulam, B., Akman, A. and Colak, M. (2014) Comparison of Intracameral Dexamethasone and Intracameral Triamcinolone Acetonide Injection at the End of Phacoemulsification Surgery. Indian Journal of Ophthalmology, 62, 861-864.

[12] Ozge, G., Ayyildiz, O., Kucukevcilioglu, M. and Mumcuoglu, T. (2015) Comparison of Intracameral Dexamethasone and Intracameral Triamcinolone Acetonide Injection at the End of Phacoemulsification Surgery. Indian Journal of Ophthalmology, 63, 287-288. https://doi.org/10.4103/0301-4738.156945

[13] Wadood, A.C., Armbrecht, A.M., Aspinall, P.A. and Dhillon, B. (2004) Safety and Efficacy of a Dexamethasone Anterior Segment Drug Delivery System in Patients after Phacoemulsification. Journal of Cataract \& Refractive Surgery, 30, 761-768. https://doi.org/10.1016/j.jcrs.2003.08.028

[14] Solaiman, K.A.M., Maaly, S., Albialy, H.A. and Desouky, R.A. (2016) Paediatric Cataract Surgery and Intraocular Lens Implantation with and without Intracameral 
Triamcinolone Acetonide. Journal of Clinical \& Experimental Ophthalmology, 7, 542-545. https://doi.org/10.4172/2155-9570.1000542

[15] Iqbal, C.J., Ali, Z., Ahmad, K.A. and Akram, M.A. (2011) Comparison of Intracameral Dexamethasone and Subconjunctival Dexamethasone in Reducing Postoperative Inflammation after Cataract Surgery. Ophthalmology Pakistan, 1, 8-11.

[16] Amr, S.B., Tamer, M.I. and Ahmed, M.R. (2017) Effect of Intracameral Dexamethasone Injection at Conclusion of Cataract Surgery on Macular Thickness in Diabetics. International Journal of Open Access Ophthalmology, 2, 1-4.

https://doi.org/10.15226/2474-9249/2/2/00124

[17] Praveen, M.R., Shah, S.K., Vasavada, V.A., Dixit, N.V., Vasavada, A.R., et al. (2010) Triamcinolone-Assisted Vitrectomy in Paediatric Cataract Surgery: Intraoperative Effectiveness and Postoperative Outcome. Journal of Cataract \& Refractive Surgery, 32, 2054-2059. 